\title{
CLASSIFICATION SCHEMES OF NONOSCILLATORY SOLUTIONS FOR TWO-DIMENSIONAL TIME SCALE SYSTEMS
}

\author{
ÖZKAN ÖZTÜRK
}

Abstract. Asymptotic properties of solutions for nonlinear systems are significant in order to obtain enough information about the behavior of systems. We deal with a two dimensional time scale nonlinear system and show the (non)existence of nonoscillatory solutions by using most well - known fixed point theorems. We also provide several examples whose solutions are known explicitly.

Mathematics subject classification (2010): 34N05, 39A10, 39A13.

Keywords and phrases: Time scales, two dimensional nonlinear time scale system, integral inequalities, nonoscillation, oscillation theory.

\section{REFERENCES}

[1] D. R. Anderson, Oscillation and Nonoscillation Criteria for Two-dimensional Time-Scale Systems of First Order Nonlinear Dynamic Equations, Electron. J. Differential Equations, vol. 2009 (2009), no. 24, pp. 1-13.

[2] M. Bohner and A. Peterson, Dynamic Equations on Time Scales: An Introduction with Applications, Birkhäuser, Boston, 2001.

[3] M. Bohner And A. Peterson, Advances in Dynamic Equations on Time Scales, Birkhäuser, Boston, 2003.

[4] M. CecChi, Z. DošLÁ, M. MARINI ANd I. VRKoč, Integral Conditions for Nonoscillation of Second Order Nonlinear Differential Equations, Nonlinear Anal. 64 (2006) 1278-1289.

[5] P. G. Ciarlet, Linear and Nonlinear Functional Analysis with Applications, Siam, 2013.

[6] B. Knaster, Un théorème sur les fonctions d'ensembles, Ann. Soc. Polon. Math. 6 (1928) 133-134.

[7] W. T. LI, Classification Schemes for Positive Solutions of Nonlinear Differential Systems, Math. Comput. Modelling 36 (2002) 411-418.

[8] Ö. ÖZtÜRK, E. AKIN, Classification of Nonoscillatory Solutions of Nonlinear Dynamic Equations on Time Scales, Dynam. Systems Appl., to appear, 2015.

[9] Ö. ÖZtÜRK, E. AKIN, İ. U. TIRYAKI, On Nonoscillatory Solutions of Emden-Fowler Dynamic Systems on Time Scales, Filomat, to appear, 2015.

[10] Ö. ÖztÜRK, E. AkIn, Nonoscillation Criteria for Two Dimensional Time Scale Systems, Nonauton. Dyn. Syst. 2016, 3: 1-13.

[11] Ö. ÖZTÜRK, E. AkIn, On Nonoscillatory Solutions of Two Dimensional Nonlinear Delay Dynamical Systems, Opuscula Math., vol. 36, no. 5 (2016).

[12] E. ZEIDLER, Nonlinear Functional Analysis and its Applications - I: Fixed Point Theorems, Springer Verlag New York Inc, 1986. 